\title{
Environmental awareness, attitude and behavior among under graduates in Malaysia
}

\begin{abstract}
This study was undertaken to evaluate the knowledge, attitude and behaviour on the environment among 650 undergraduates. The representative samples were selected through a two-stage sampling method. The validated questionnaires developed by the Focus Group Discussion (FGD) process and expert opinions were utilized in this study. The pre-testing of the questionnaire was carried out among 50 undergraduates. Explanatory Factor Analysis revealed three components existed in the questionnaire, namely knowledge, attitude and behavior. Each Component shows good reliability, awareness component (8 questionsठ Cronbach Alpha0.72), attitude (9 questionsð Cronbach Alpha-0.78) and behavior (8 questions, Cronbach Alpha 0.70). This study revealed the level of environmental knowledge and attitudes among students was high 4:15(sd0.42) and 4:19(sd0.49), however, they score moderately on behavior component $(3.20(\operatorname{sd} 0.46)$. There are no significant difference in awareness, attitude and behaviour between gender, However, different age groups differed significantly (4.24 vs. 4.14, $\mathrm{p}=0.013)$. Meanwhile, the awareness score was also significantly different between undergraduates from different programs (4.11 vs. $4.20, \mathrm{p}=$ 0.005). Multivariable Linear Regression indicates the positive association between high knowledge and attitudes with pro-environmental behavior.
\end{abstract}

Keyword: Environmental awareness; Attitude; Behavior; Undergraduates; Malaysia 